\title{
Developing a Core Set to Describe Functioning in Vocational Rehabilitation Using The International Classification of Functioning, Disability, and Health (ICF)
}

\author{
Reuben Escorpizo $\cdot$ Jan Ekholm $\cdot$ \\ Hans-Peter Gmünder • Alarcos Cieza • \\ Nenad Kostanjsek • Gerold Stucki
}

Published online: 1 June 2010

(C) Springer Science+Business Media, LLC 2010

\begin{abstract}
Introduction the consequences of accidents, injuries, and health conditions that prevent workers from engaging in employment are prevailing issues in the area of work disability. Vocational rehabilitation (VR) programs aim to facilitate return-to-work process but there is no universal description of functioning for patients who participate in VR. Our objective is to develop a Core Set for VR based on the international classification of functioning, disability, and health (ICF). An ICF Core Set is a short list of ICF categories with alphanumeric codes relevant to a health condition or a health-related event. Methods
\end{abstract}

\section{R. Escorpizo · G. Stucki}

Department of Health Sciences and Health Policy, University

of Lucerne, Lucerne, Switzerland

e-mail: reuben.escorpizo@paranet.ch

R. Escorpizo · A. Cieza · G. Stucki $(\square)$

Swiss Paraplegic Research (SPF), Nottwil, Switzerland

e-mail: gerold.stucki@paranet.ch

R. Escorpizo · A. Cieza · G. Stucki

ICF Research Branch, WHO FIC CC Germany (DIMDI) at SPF,

Nottwil, Switzerland

R. Escorpizo · A. Cieza - G. Stucki

ICF Research Branch, WHO FIC CC Germany (DIMDI)

at IHRS, Ludwig Maximilian University, Munich, Germany

J. Ekholm

Division of Rehabilitation Medicine, Department of Clinical

Sciences DS, Karolinska Institutet and Danderyd University

Hospital, Stockholm, Sweden

H.-P. Gmünder

Rehaklinik Bellikon, Bellikon, Switzerland

N. Kostanjsek

World Health Organization, Classification, Terminology

and Standards, Geneva, Switzerland development process consists of three phases. First is the preparatory phase which consists of four parallel studies: (1) systematic review of the literature, (2) worldwide survey of experts, (3) cross-sectional study, and (4) focus group interview. Patients with various health conditions are to be recruited from five VR centers located in Switzerland and Germany. The second phase is a consensus conference where findings from the preparatory phase will be presented followed by a multi-stage consensus process to determine the ICF categories that will comprise the Core Set for VR. The final phase consists of validation studies in several health conditions and settings. Conclusions we expect the first version of the ICF Core Set for VR to be completed in 2010. The Core Set can serve as a guide in the evaluation of patients and in planning appropriate intervention within VR programs. This Core Set could also provide a standard and common language among clinicians, researchers, insurers, and policymakers in the implementation of successful VR.

Keywords Vocational rehabilitation - Work · Employment · ICF · Classification · Reintegration

\section{Introduction}

Accidents, injuries, and other health conditions preventing workers from engaging in gainful employment are major and prevailing issues in the area of functioning and disability. Global estimated yearly loss in terms of the Gross Domestic Product is up to US\$ 1.9 trillion because of "social exclusion from the workplace" [1]. About $72 \%$ of people with some form of disability in the world are of working age, according to the International Labour Organization (ILO) [2]. Work-related injuries and illnesses are 
global matters that are associated with great social and economic consequences such as work loss, productivity loss, increased medical care-related expenses, and indirect costs such as time missed from work due to a health condition $[3,4]$. Low level of health-related quality of life and poor psychological and physical functioning have all been linked to lack of work participation [5]. Further, health conditions do not only affect work participation but could, in turn, burden the patient's family [6] and caregiving functions [7] and could negatively affect the worker's role within his or her family and the community at large [8].

Given the consequences of health conditions or health events such as sick leave or absenteeism and limited work participation, vocational rehabilitation becomes crucial generally, in the area of disability management and, specifically, in the process of returning the worker back to work. It is then essential that clinicians, researchers, policymakers, and other stakeholders have a standard platform that is able to capture the functioning of individuals who are referred to vocation rehabilitation programs to ensure comparison of care and efficient communication between key players. Such standardization may contribute to successful intervention and sustained return-to-work. Vocation or work is a major life area to most people, yet there is no universal approach to describe the domains that are important to evaluate when individuals undergo vocational rehabilitation.

The purpose of this paper is to present and discuss the international project on the ICF Core Set development for vocational rehabilitation. Specific aims of the paper are (1) to define vocational rehabilitation within the context of the project, (2) to discuss the role of the International Classification of Functioning, Disability and Health [9] in vocational rehabilitation, and (3) to present the multi-perspective studies with the objectives, methodologies, expected outcomes (results are not presented in this article), and implications to the field of vocational rehabilitation.

\section{Defining Vocational Rehabilitation}

Individuals with health-related limitation or restriction, regardless of the health condition that interfere with their work, may be referred to vocational rehabilitation. The terminology vocational rehabilitation comes from the word "vocation", which is the Latin for "summons" or "call", to a particular state or action. It could be applied to positions of work, employment, occupation, or special function [10]. Vocational rehabilitation has been used interchangeably with return-to-work [11], occupational rehabilitation [12], and work rehabilitation [13]. Rehabilitation, on the other hand, is from the Medieval Latin word "rehabilitatus", which means to restore to former capacity or to former state. It is defined as a process of bringing to a condition of health of "useful activity" [10].

The ILO provides objectives for vocational rehabilitation as a process that enables a person with disability to secure and retain suitable employment and embodies the idea of integration or reintegration of the person into the society. Vocational rehabilitation may include specialized vocational guidance and counselling, vocational training and placement, and employment [14], to name a few. Selander [15] referred to vocational rehabilitation as a process consisting of "medical, psychological, social, and occupational activities" among sick or injured people with work history to "re-establish" work capacity to return to work force. Vocational rehabilitation plays a key process in various settings such as mental health [16, 17] and may even be a critical determinant in engaging individuals to work but have not worked prior to the health event (e.g. childhood-onset conditions, intellectual disability, etc.) [18, 19]. Marnetoft et al. [20] considered several components of vocational rehabilitation to include vocational guidance (e.g. counselling), work re-training, education, ergonomics, and psychosocial programs. Important factors that needed to be considered within vocational rehabilitation may include personal and psychosocial factors, medical factors, the employer and the workplace, and the socioeconomics [21]. The application of vocational rehabilitation can be useful in different health conditions such as those that are physical or psychological in nature [22]. Therefore, vocational rehabilitation is a complex of interventions which require more than one discipline to ensure success. Therefore, vocational rehabilitation is a multidisciplinary approach, the aim of which is to return or engage a worker towards gainful employment. It is an often multitiered process which consists of multiple players and relates the functioning of the individual worker with work role in the broadest sense. The list of various services mentioned here is not necessarily exhaustive of the entire vocational rehabilitation.

A successful vocational rehabilitation program rely on the interrelationship between several elements such as the workplace commitment, accommodation made by the employer, return-to-work coordinators and planners, supervisors, early intervention, and effective communication between the employer and health care provider [23]. There are benefits to vocational rehabilitation-it has been found to reduce work day lost and reduction in work-related disability and facilitate early return to work [24, 25]. Early vocational rehabilitation has been associated with sustained employment $[13,26]$ and have been proven to result in decrease in sickness absence of workers over time [25, 2730]. In terms of economics, vocational rehabilitation was found to result in favourable cost-benefit ratio [31], potentially leading to good cost savings for the employers. 
Early studies have suggested multiple factors that were associated with successful vocational rehabilitation or return-to-work programs. Sheikh and Mattingly [32] pointed out that motivation, less severe physical disability, short unemployment duration prior to rehabilitation, completion of rehabilitation, and low unemployment in the injured worker's home area all contributed to successful return-to-work outcomes. Physical restoration and retraining indicated good return-to-work outcomes in a study among work disabled individuals with arthritis [33]. Selander et al. [21] reviewed the risk factors around returnto-work and found that younger age, those with high education, married, have social support, with self-confidence, good perceived quality of life and health, those who have high level of control, those with less pain, disability and medical complication, those that underwent multidisciplinary approach to rehabilitation, and those who had patient education have had positive vocational rehabilitation outcomes. Moreover, those who have favourable (physical and psychosocial) work environment, have an option to modify the job, with wide decision latitude, and those with less disability compensation were also likely to return to work [21]. Based on the findings from these studies, it is evident that vocational rehabilitation involves various factors around the worker, his or her work, his or her workplace, and beyond the traditional confines of "work" (even to include societal and household role and overall quality of life). Given all these considerations, it may be favourable to have a unifying, inclusive, and generic framework that look at these different factors.

A wide variation exists in terms of defining vocational outcomes. Vocational outcomes may be in the form of being unable to perform normal duty, a temporary job reassignment, working less than full time, filing a workers' compensation claim, or quitting or being fired due to injury [12]. Evaluation of these outcomes differs between nations and across practice or health care settings. There is evidence to suggest international variability of how vocational rehabilitation is being conducted and operationalized and its overarching influence on social systems [34, 35]. Vocational rehabilitation services and outcomes have been investigated in several health conditions such as traumatic brain injuries [36], individuals with psychiatric disabilities [37], spinal cord injuries [38], multiple sclerosis [39, 40], stroke [41, 42], chronic illness [43], brain injury [44], amputation [45], burn [5], and musculoskeletal conditions $[27,46]$. Given the variability of the vocational outcomes in different health conditions and practice settings, it becomes imperative that we are able to provide and capture a clear description of functioning within the context of work or vocation and to lay out a foundation for universal communication and understanding between and among healthcare providers, insurers, employers, and other stakeholders. This universality may be provided by the ICF of the World Health Organization. The international community of vocational rehabilitation would need an ICFbased Core Set that would be crucial to the assessment and evaluation of workers and ultimately when planning intervention and monitoring work outcomes for clinical, research, and policy purposes.

The ICF as a Model of Functioning in Vocational Rehabilitation

Rothstein and Echternach [47] stated that one could not measure what one does not know, and one cannot evaluate what one did not measure. Since the field of vocational rehabilitation is broad and multifaceted to begin with, there will be challenges to describe and measure vocation-related domains and we would also need a universal framework that could be used in describing the domains. A conceptual framework or classification system that is approved by the World Health Organization implies universal acceptability for potential use in various settings to include vocational rehabilitation. The ICF, which was approved by the 54th World Health Assembly in 2001, offers a classification system to describe human functioning and health [9] that can be helpful to systematically understand the different domains around functioning and that could cover the full spectrum of an individual's lived experience (see Fig. 1). This classification was intended by the World Health Organization to be used as an "international standard to describe and measure health and disability" [48]. The ICF framework is based on the biopsychosocial model of health and disability and recognises the complex interaction between its different components: body functions, body structures, activities and participation, environmental factors, and personal factors. Each component of the ICF (except for personal factors) has several chapters. A brief description of the general contents of each chapter is provided in Fig. 2. We refer the readers to the ICF Handbook [9] if further information about the ICF is desired. It is also important to recognize that the ICF in this project would be used as a guiding generic framework as it has been in other previous similar projects $[49,50]$, while also being aware that there are other work-specific models that could be used alongside the ICF [51-53].

The ICF could be a viable framework to be used in vocational rehabilitation settings. The benefit of using the ICF in vocational rehabilitation programs such as in job placement, for example, has been exemplified [54]. There are several features of the ICF that make it favourable for use in vocational rehabilitation. First feature is its universality to aid thought process-the comprehensive conceptualization of outcomes in the field of vocational rehabilitation and work disability in general. Second 


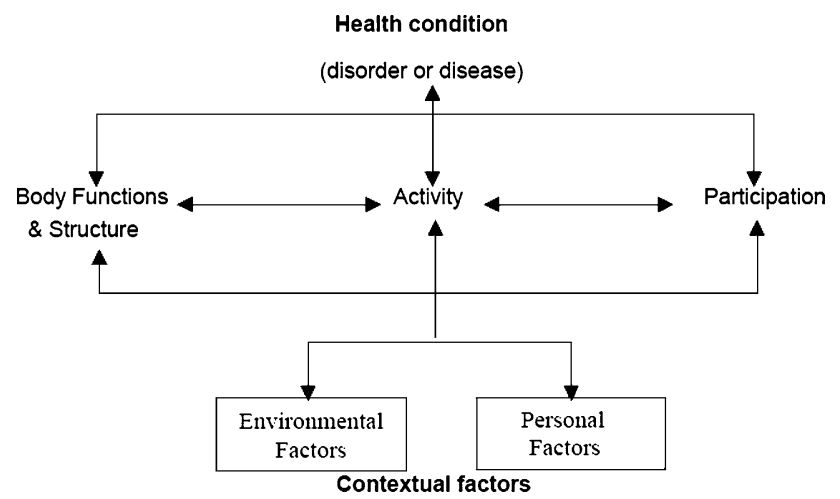

Fig. 1 Components of the ICF model

\begin{tabular}{|c|c|c|c|}
\hline $\begin{array}{l}\text { Body functions } \\
\text { (Chapters b1 - b8) }\end{array}$ & $\begin{array}{l}\text { Body structures } \\
\text { (Chapters s1 - s8) }\end{array}$ & $\begin{array}{l}\text { Activities and } \\
\text { Participation } \\
\text { (Chapters d1 - d9) }\end{array}$ & \begin{tabular}{|l|} 
Environmental \\
Factors (Chapters \\
e1-e5)
\end{tabular} \\
\hline $\begin{array}{l}\text { b1 Mental functions } \\
\text { b2 Sensory } \\
\text { functions and pain } \\
\text { b3 Voice and } \\
\text { speech functions } \\
\text { b4 Functions of the } \\
\text { cardiovascular, } \\
\text { haematological, } \\
\text { immunological and } \\
\text { respiratory systems } \\
\text { b5 Functions of the } \\
\text { digestive, } \\
\text { metabolic and } \\
\text { endocrine systems } \\
\text { b6 Genitourinary } \\
\text { and reproductive } \\
\text { systems } \\
\text { b7 } \\
\text { Neuromusculoskel } \\
\text { etal and } \\
\text { movement-related } \\
\text { functions } \\
\text { b8 Functions of the } \\
\text { skin and related } \\
\text { structures }\end{array}$ & $\begin{array}{l}\text { s1 Structures of the } \\
\text { nervous system } \\
\text { s2 The eye, ear } \\
\text { and related } \\
\text { structures } \\
\text { s3 Structures } \\
\text { involved in voice } \\
\text { and speech } \\
\text { s4 Structures of the } \\
\text { cardiovascular, } \\
\text { immunological and } \\
\text { respiratory systems } \\
\text { s5 Structures } \\
\text { related to the } \\
\text { digestive, } \\
\text { metabolic and } \\
\text { endocrine systems } \\
\text { s6 Structures } \\
\text { related to } \\
\text { Genitourinary and } \\
\text { reproductive } \\
\text { systems } \\
\text { s7 Structures } \\
\text { related to } \\
\text { movement } \\
\text { s8 Skin and related } \\
\text { structures }\end{array}$ & $\begin{array}{l}\text { d1 Learning and } \\
\text { applying } \\
\text { knowledge } \\
\text { d2 General tasks } \\
\text { and demands } \\
\text { d3 Communication } \\
\text { d4 Mobility } \\
\text { d5 Self-care } \\
\text { d6 Domestic life } \\
\text { d7 Interpersonal } \\
\text { interactions and } \\
\text { relationships } \\
\text { d8 Major life areas } \\
\text { d9 Community, } \\
\text { social and civic life }\end{array}$ & $\begin{array}{l}\text { e1 Products and } \\
\text { technology } \\
\text { e2 Natural } \\
\text { environment and } \\
\text { human-made } \\
\text { changes to } \\
\text { environment } \\
\text { e3 Support and } \\
\text { relationships } \\
\text { e4 Attitudes } \\
\text { e5 Services, } \\
\text { systems and } \\
\text { policies }\end{array}$ \\
\hline
\end{tabular}

Fig. 2 Chapters of each component of the ICF. Note: Chapters do not have to numerically correspond to each other per component. For example, b1 Mental function is not necessarily equivalent to s1, d1, or e1

feature of the ICF is the inclusive classification system that can be applied to structure the domains in and around work or vocation. Third feature, the ICF gives recognition and consequent definition (through the ICF categories) to a variety of factors that could facilitate or hinder successful and sustained return to work because the ICF considers the influence of contextual factors such as those pertaining to the environment and to the individual (person), Participation of individuals in the society is a core element of the ICF and this brings a broad perspective to functioning and disability. Therefore, the ICF is a framework for understanding health at different levels-from the micro work environment to the macro work environment and the relationship between the two. Finally, with the ICF it is possible to examine group level data across conditions or interventions for an efficient, transparent, and cost-effective health care [55] that would be compatible for crossanalysis.

\section{The ICF Core Sets}

The ICF includes more than 1,400 categories (i.e. descriptors) to describe the full human experience of functioning so it may not be feasible and practical to use all these categories in clinical encounters or research studies. To resolve this issue, efforts toward the development of ICF Core Sets [56] have been undertaken. A Core Set refers to a short list of ICF categories that are relevant and can be used in a given health condition (e.g. osteoarthritis) or health-related event (e.g. vocational rehabilitation). A Core Set can be in two forms, namely, the comprehensive and brief version. A comprehensive Core Set is usually utilized in multi-disciplinary assessment and which has as few categories as possible to be practical, but as many as possible to capture the spectrum of variables of the conditions. A brief Core Set contains the minimum number of measures or categories that are to be included in studies (such as clinical trials) pertaining to a health condition or event. There are several condition-specific Core Sets that are available [50, 57-61]. The use of condition-specific Core Sets is beneficial because it makes the clinical encounter both thorough and efficient [62] while still applying the ICF framework. The development of Core Sets, in collaboration with the WHO and the ICF Research Branch (Collaborating Center for the Family of International Classifications) observe similar methodology and conduct preparatory studies in various countries around the world [63].

\section{Objective of the Project}

The overall objective of our project is to develop an ICFbased Core Set to describe the functioning and health of individuals who participate in multidisciplinary vocational rehabilitation. This Core Set could serve as a guide on measures to help clinicians and researchers implement optimal rehabilitation programs for individuals of working age with limited work ability due to disease or injury. In addition, the Core Set is meant to cover a broad spectrum of health conditions and types of job. Specific aims of the project are (1) to identify what factors are important and relevant to vocational rehabilitation from the different perspectives, (2) to obtain the first version of the ICF Core Set for vocational rehabilitation based on a consensus 
conference, and (3) to test and validate the first version of the Core Set in various settings and applications.

\section{Materials and Methods}

\section{Stages of the Core Set Development}

The project will be conducted in stages: (1) preparatory phase, (2) consensus conference, and (3) validation phase. The process is similar to other core sets that have been developed to date (Fig. 3).

Phase 1: Preparatory Phase

The project consists of four preparatory studies that are conducted in parallel: (1) systematic review of the literature, (2) worldwide expert survey, (3) cross-sectional study, and (4) focus group interview. A brief description of each study is provided below.

\section{Systematic Review: Literature Perspective}

The objective of the systematic review is to identify the different patient-reported and clinician-reported outcomes that were measured in the studies found. A structured search strategy will be implemented using multiple databases including CINAHL, PsycInfo, Medline, Global Health, and Vocational and Career Collection. Search terms include "vocational rehabilitation" OR "return to work" OR "occupational rehab*" OR "work rehab*", "work reintegration" OR "job rehab*" OR "job reentry" OR "employ* rehab*" OR "employ* reentry". Search for articles is limited to those published between 2004 and 2008, peer-reviewed, with available abstract, must be written in the English language, and studies conducted with adults of working age (18-65 years old). Articles are

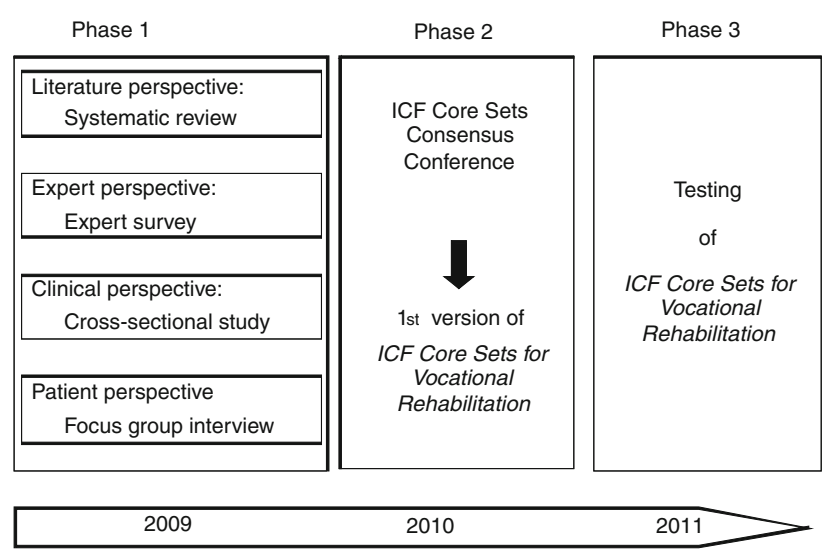

Fig. 3 Development process of the ICF Core Set for vocational rehabilitation excluded if they are editorials, comments, letter, book chapters, conference proceedings, not specific to vocational rehabilitation setting or intervention, phase 1 and 2 clinical trials, development of scales or measures, systematic review, meta analysis, and genetic studies. Other available search strategies will also be used as reference [64, 65].

Two independent researchers are randomly assigned the studies collected and will perform the abstract and full text screening to identify measures and variables that have been utilized in each included study. Agreement will be examined on included and excluded studies. Concepts will be identified from each measure and will be linked to the ICF and then an analysis of the most frequent ICF categories addressed in those measures will be performed. Studies will not be rated based on quality or level of evidence at this time.

\section{Global Survey: Expert Perspective}

The objective of the expert survey is to identify factors or variables that are important in individuals undergoing vocational rehabilitation. Experts from all over the world will be systematically identified and invited to participate in the expert pool from which respondents will be randomly selected by profession and WHO region.

An "expert" in vocational rehabilitation is arbitrarily defined as a healthcare professional (broadly defined as an individual who looks after the vocational rehabilitation participants within a healthcare setting), has at least 2 years of experience in vocational rehabilitation, and can effectively communicate in English. Experts can be physicians, physical therapists, occupational therapists, psychologists, social workers, vocational counsellors, nurses, and case managers. Experts will be identified from 6 WHO regions: Africa, the Americas, South-East Asia, Europe, the Eastern Mediterranean, and the Western Pacific. Names and contact information will be obtained through the systematic review of the literature, professional organizations, partner societies, informal network, peers, internet search, and referral from experts already contacted.

The survey will be conducted over the internet (webbased). Experts will be asked open-ended questions regarding what factors should be considered when evaluating and treating patients in vocational rehabilitation. From the experts' responses, concepts will be identified and linked to the ICF by two independent researchers (i.e. linkers) and then frequency analysis and the level of agreement between the two linkers will be calculated.

\section{Cross-Sectional Study: Clinical Perspective}

The objective of the cross-sectional study is to identify quantitatively what aspects of functioning are problematic 
among individuals undergoing vocational rehabilitation. The cross-sectional study will consist of individual structured interviews of clinicians and documentation of patient encounters from the participating study centers. An extended ICF checklist [66] will be clinician-administered, assessing the patient's level of functioning. The clinician will also obtain additional information from the patient's medical record. In addition, patient-reported questionnaires, such as the comorbidity questionnaire [67], Beck Depression Inventory II [68], Medical Outcome Study Short Form 36 [69], and World Health Organization Quality of Life Questionnaires [70], will also be administered.

\section{Focus Group Interview: Patient Perspective}

The objective of the focus group study is to identify qualitatively what aspects of functioning are problematic among individuals undergoing vocational rehabilitation. Qualitative methodology will be used through focus group interview with open-ended questions to identify and discuss body structures and functions, activities and participation, environmental factors, and personal factors-all of which may hold relevance to the patients. Four to six patients for each group and up to eight groups are planned, or until saturation is observed. A study coordinator will perform the verbatim transcription. From the patients' responses, concepts will be identified and linked to the ICF by two independent researchers (i.e. linkers). Frequency analysis and the level of agreement between the two linkers will be calculated.

\section{Participants and Study Centers: Cross-Sectional and Focus Group Studies}

Patients who will participate in the cross-sectional study and focus group interview will be recruited from multiple study centres. These patients have been referred to vocational rehabilitation. Reasons for referral include limited or restricted vocational engagement of the worker due to various health conditions or events such as but not limited to traumatic injuries, chronic illnesses and chronic pain, arthritis, and psychiatric diseases and behavioural disorders.

There are five vocational rehabilitation centers which will participate in the cross-sectional study and focus group interviews. All the study centers provide multidisciplinary vocational rehabilitation services and programs. Four centers are in Switzerland and one in Germany. Ethics approvals for all study centers have been approved.

\section{Phase 2: Consensus Conference}

Selected experts in the field of vocational rehabilitation from different health professions and from all WHO regions will be invited to attend a consensus conference (data-driven and iterative process) scheduled in 2010 in Switzerland. In this conference, findings from the four studies (phase 1) will be presented so the invited experts are informed of the different perspectives in vocational rehabilitation. A multi-stage consensus process will follow where invited experts will decide on the list of ICF categories to be included in the first version of the ICF Core Set for vocational rehabilitation.

\section{Phase 3: Testing and Validation}

During this phase, the first version of the Core Set will undergo testing and validation using various methodologies. The Core Set will also be validated in different work settings (e.g. physical vs. mental jobs), and health conditions (e.g. physical vs. mental conditions, musculoskeletal vs. neurological conditions, etc.). Due to the relation of vocational rehabilitation to various aspects of disability, the Core Set we intend to develop can be an important input from the vocational rehabilitation community and consequently may be applied in social security setting and disability eligibility determination. These possibilities could be explored in this phase.

\section{Discussion}

Work or vocation is a major life area to most people. Health condition or health-related events could impact functioning and prevent individuals from engaging with their work life. Vocational rehabilitation plays an essential role in the area of addressing work disability and at the same time encouraging participation of individuals in the society and workforce. As a program, vocational rehabilitation is fundamental in mitigating work disability and could contribute to improve overall quality of life. Therefore, a systematic understanding and measurement of the factors around vocational rehabilitation and their effects on the functioning and health of the individual would be helpful. While current literature supports the benefits of rehabilitating workers towards gainful and sustained employment, a Core Set of variables and measures for vocational rehabilitation that is based on the ICF by the WHO is not available. With this in mind, we will pursue a project that would determine an ICF Core Set for vocational rehabilitation which would provide a common ground of understanding and description of functioning in the vocational rehabilitation setting. In order to achieve this goal, we will conduct multiple-perspective studies, consensus process, and validation studies.

We see broad applications and benefits of developing an ICF Core Set for vocational rehabilitation. Such a Core Set 
will make the ICF practical to the end users including clinicians, researchers, service providers, insurance, and policymakers by providing a common language and standard in the evaluation and reporting of vocation-related outcomes to manage patients and improve rehabilitation programs. We expect that that the Core Set can be used by healthcare service providers regardless of their health profession. We also see the use of the Core Set in wide range of health conditions. Moreover, the Core Set with its viable interface with the International Classification of Diseases [71] could complement medical reporting and enhance health information system. In the practice of vocational rehabilitation where workers might have a great variation of work environments, the Core Set is in a position to integrate concepts pertinent to the "environment" within "work" context, which in our opinion is an important piece of how the complexities around work can be made operational. In the realm of clinical decisionmaking, the Core Set could advance the thought process by which clinicians identify the underlying problems (i.e. impairment, limitation, restriction, barriers, and facilitators) and to consequently help them plan appropriate clinical care.

Initially, the vocational rehabilitation Core Set will be independent of the health condition and job type. In our opinion, the first version of the Core Set will benefit the multiple stakeholders including those who fund care (e.g. insurance) from the vocational rehabilitation community. Later, the Core Set may be compared and validated and may be found to be similar (or not) to other existing ICF Core Sets for other health conditions or the ICF Generic Core Set [72]. From a social perspective, the Core Set on vocational rehabilitation could also be compared to the existing Core Set on social security [49] to explore ways to better enhance assessments in disability benefit claims and if indeed vocational rehabilitation is part of a continuum of eligibility determination for disability claims. It might be interesting to have a closer look at the interdependence of the Core Set serving as the minimum number of measures that need to be evaluated in addition to the social security measures of one country or region. The variation in job type could be also validated later by performing an examination of a job-skill requirement list such as that of O'NET (http://online.onetcenter.org/). The Core Set can be "matched" to a particular job description depending on the required capacity and skills. This way the variability that is being introduced by the job type of individuals in vocational rehabilitation will be taken into account.

The project has several strengths: The development process is multi-perspective, rigorous, data-driven, and iterative. The Core Set can be applied in both research investigations and clinical settings. The Core Set can be utilized as fundamental metrics in clinical practice, clinical trials, intervention studies and has great potential use when integrated into educational curriculum or continuing education for occupational health and vocational rehabilitation professionals, and has its use as a framework for workrelevant social and health policy. It is also important to recognize that the ICF Core Set (generic as it is) could complement other specific existing frameworks in the field of vocational rehabilitation.

The project also has some limitations. The resulting Core Set may be too broad or too generic because it will cover a wide spectrum of health conditions, health professionals, and job types. Therefore, it might loose some level of precision when it comes to measurement of certain outcomes given a specific setting. The Core Set will also not be able to provide concrete ways by which the included ICF categories can be made operational. In other words, at this time the Core Set can only indicate "what" to measure and not "how" to measure. However, it is our opinion that the issue of precision and operationalization can be further investigated by planning future studies in the final and rigorous phase of the project. Within the context of vocational rehabilitation, it is important to recognize the importance of understanding factors that are attributed to the worker as a person [73-75] and it is an evolving area that needs to addressed further. Personal factors component of the ICF is not yet categorized in the current version of the ICF. While this may lead to a gap in the characterization attributed to the individual worker and how it affects the return-to-work process, the project will document "personal factors" around vocational rehabilitation that have been found to be important so the information on the "person" is not really lost. We are aware of some methodological challenges. One challenge with a qualitative study is the threat to external validity. While the results of the study may not necessarily be generalizable across settings or treatment conditions [76], focus groups when used with prudence can be useful in examining emerging concepts [77] and depending on the nature of its application to a specific environment or setting [76]. Moreover, while it may be sensible to conduct the studies in series rather than in parallel, studies are conducted simultaneously for practicality (i.e. time) concern and also to ensure the standard procedure that was observed with other Core Set projects. In the consensus part of the process, we recognize the possibility of participation bias and "personality dominance". Consensus type of process, however, has been previously implemented and was found to be helpful in crafting recommendations and developing guidelines based on scientific data and iterative process [78, 79].

The majority of people engage in some form of work or vocation in their lives. Health conditions or health-related events may happen that would limit or restrict a person's 
ability to work which makes vocational rehabilitation important to facilitate early, successful, and sustained return-to-work. We need a framework and classification system that could be used as a standard or common language that can be used in the vocational rehabilitation settings by different healthcare providers and understood by different stakeholders. Therefore, we will develop a Core Set based on the ICF to achieve this.

\section{Steering Group}

The ICF Core Set development for vocational rehabilitation project has an International Steering Committee and a Local Advisory Group. Members of the Steering Committee include the Classification, Terminology and Standards Department of the World Health Organization (WHO), the World Confederation for Physical Therapy (WCPT), the World Federation of Occupational Therapists (WFOT), the International Labour Organization (ILO), the International Society of Physical and Rehabilitation Medicine (ISPRM), Prof. Alessandro Giustini and Prof. Jan Ekholm. The Local Advisory Group consists of individuals from the study centers, and a patient advocacy group: Dr. Peter Erhart, Dr. Ulrike Hoffmann-Richter, Stefan Ritler, Kurt Gfeller, Cornelia Bachofner, Carl Gennheimer, Prof. Olivier Deriaz, Dr. Gilles Rivier, Franco Lanfranchi, Dr. Andreas Klisptein, Dr. Hans-Martin Schian, and Dr. Christian Wenk. The Swiss Accident Insurance of Switzerland (SUVA) is funding the project.

Acknowledgments Special thanks to Teresa Brinkel, Monika Finger, Andrea Glässel, Miriam Lückenkemper, Dr. Kristina SchüldtEkholm, study centers' coordinators and staff, the ICF Research Branch, the Swiss Paraplegic Research, and project collaborators.

\section{References}

1. Metts RL. Disability issues, trends and recommendations for the World Bank. Washington: World Bank; 2000.

2. International Labour Organization. ILO calls for new efforts to support people with disabilities in the world of work. Geneva, International Labour Organization [webpage on the internet]. Available from: http://www.ilo.org/public/english/support/lib/ resource/subject/disability.htm.

3. Hansson EK, Hansson TH. The costs for persons sick-listed more than one month because of low back or neck problems. A twoyear prospective study of Swedish patients. Eur Spine J. 2005;14: 337-45.

4. Carlos-Rivera F, Aguilar-Madrid G, Gomez-Montenegro PA, Juarez-Perez CA, Sanchez-Roman FR, Durcudoy Montandon JE, et al. Estimation of health-care costs for work-related injuries in the Mexican Institute of Social Security. Am J Ind Med. 2009;52:195-201.

5. Dyster-Aas J, Kildal M, Willebrand M. Return to work and health-related quality of life after burn injury. J Rehabil Med. 2007;39:49-55.
6. Ellenbogen PS, Meade MA, Jackson MN, Barrett K. The impact of spinal cord injury on the employment of family caregivers. J Vocat Rehabil. 2006;25:35-44.

7. Franche RL, Pole JD, Hogg-Johnson S, Vidmar M, Breslin C. The impact of workrelated musculoskeletal disorders on workers' caregiving activities. Am J Ind Med. 2006;49:780-90.

8. Dembe AE. The social consequences of occupational injuries and illnesses. Am J Ind Med. 2001;40:403-17.

9. World Health Organization. International classification of functioning, disability, and health: ICF. Geneva: World Health Organization; 2001.

10. Merriam-Webster. [webpage on the internet]. Available from: http://www.merriamwebster.com/dictionary/.

11. Glozier N, Hackett ML, Parag V, Anderson CS. Auckland Regional Community Stroke (ARCOS) Study Group. The influence of psychiatric morbidity on return to paid work after stroke in younger adults: the Auckland Regional Community Stroke (ARCOS) Study, 2002 to 2003. Stroke. 2008;39:1526-32.

12. Dembe AE, Delbos R, Erickson JB, Banks SM. Associations between employees' work schedules and the vocational consequences of workplace injuries. J Occup Rehabil. 2007;17:641-51.

13. Gard G, Soderberg S. How can a work rehabilitation process be improved?-a qualitative study from the perspective of social insurance officers. Disabil Rehabil. 2004;26:299-305.

14. International Labour Organization. Convention concerning vocational rehabilitation and employment (disabled persons). Geneva: International Labour Organization, 1983;C159(69).

15. Selander J. Unemployed sick-leavers and vocational rehabilitation - a person level study based on a national social insurance material. Ph. D. thesis. Karolinska Institutet, Department of Rehabbilitation Medicine, Stockholm, Sweden; 1999.

16. Blankertz L, Robinson S. Adding a vocational focus to mental health rehabilitation. Psychiatr Serv. 1996;47:1216-22.

17. Crowther R, Marshall M, Bond G, Huxley P. Vocational rehabilitation for people with severe mental illness. Cochrane Database Syst Rev. 2001;2:CD003080.

18. Anderson V, Brown S, Newitt H, Hoile H. Educational, vocational, psychosocial, and quality-of-life outcomes for adult survivors of childhood traumatic brain injury. J Head Trauma Rehabil. 2009;24:303-12.

19. Kirsh B, Stergiou-Kita M, Gewurtz R, Dawson D, Krupa T, Lysaght R, et al. From margins to mainstream: what do we know about work integration for persons with brain injury, mental illness and intellectual disability? Work. 2009;32:391-405.

20. Marnetoft SU, Selander J, Bergroth A, Ekholm J. Factors associated with successful vocational rehabilitation in a Swedish rural area. J Rehabil Med. 2001;33:71-8.

21. Selander J, S- Marnetoft, Bergroth A, Ekholm J. Return to work following vocational rehabilitation for neck, back and shoulder problems: risk factors reviewed. Disabil Rehabil. 2002;24:704-12.

22. Beveridge S, Fabian E. Vocational rehabilitation outcomes: relationship between individualized plan for employment goals and employment outcomes. Rehanil Couns Bull. 2007;50:238.

23. Franche RL, Cullen K, Clarke J, MacEachen E, Frank J, Sinclair $\mathrm{S}$, et al. Workplace-based return-to-work interventions: a systematic review of the quantitative and qualitative literature (Summary). Institute for Work and Health; 2004. p. 5-9.

24. Norrefalk JR, Ekholm K, Linder J, Borg K, Ekholm J. Evaluation of a multiprofessional rehabilitation programme for persistent musculoskeletal-related pain: economic benefits of return to work. J Rehabil Med. 2008;40:15-22.

25. Karrholm J, Ekholm K, Ekholm J, Bergroth A, Ekholm KS. Systematic cooperation between employer, occupational health service and social insurance office: a 6-year follow-up of vocational rehabilitation for people on sick-leave, including economic benefits. J Rehabil Med. 2008;40:628-36. 
26. DeSouza M, Sycamore M, Little S, Kirker SG. The Papworth early rehabilitation programme: vocational outcomes. Disabil Rehabil. 2007;29:671-7.

27. Bultmann U, Sherson D, Olsen J, Hansen CL, Lund T, Kilsgaard J. Coordinated and tailored work rehabilitation: a randomized controlled trial with economic evaluation undertaken with workers on sick leave due to musculoskeletal disorders. J Occup Rehabil. 2009;19:81-93.

28. Jensen IB, Busch H, Bodin L, Hagberg J, Nygren A, Bergstrom G. Cost effectiveness of two rehabilitation programmes for neck and back pain patients: a seven year follow-up. Pain. 2009;142: 202-8.

29. Suoyrjo H, Oksanen T, Hinkka K, Kivimaki M, Klaukka T, Pentti $\mathrm{J}$, et al. The effectiveness of vocationally oriented multidisciplinary intervention on sickness absence and early retirement among employees at risk: an observational study. Occup Environ Med. 2009;66:235-42.

30. Murphy L, Chamberlain E, Weir J, Berry A, Nathaniel-James D, Agnew R. Effectiveness of vocational rehabilitation following acquired brain injury: preliminary evaluation of a UK specialist rehabilitation programme. Brain Inj. 2006;20:1119-29.

31. Turner-Stokes L. Evidence for the effectiveness of multi-disciplinary rehabilitation following acquired brain injury: a synthesis of two systematic approaches. J Rehabil Med. 2008;40:691-701.

32. Sheikh K, Mattingly S. Employment rehabilitation: outcome and prediction. Am J Ind Med. 1984;5:383-93.

33. Straaton KV, Harvey M, Maisiak R. Factors associated with successful vocational rehabilitation in persons with arthritis. Arthritis Rheum. 1992;35:503-10.

34. Stubbs J, Deaner G. When considering vocational rehabilitation: describing and comparing the Swedish and American systems and professions. Work. 2005;24:239-49.

35. Sim J. Improving return-to-work strategies in the United States disability programs, with analysis of program practices in Germany and Sweden. Soc Secur Bull. 1999;62:41-50.

36. Johnstone B, Reid-Arndt S, Franklin KL, Harper J. Vocational outcomes of state vocational rehabilitation clients with traumatic brain injury: a review of the Missouri Model Brain Injury System Studies. NeuroRehabilitation. 2006;21:335-47.

37. Rogers ES, Anthony WA, Lyass A, Penk WE. A randomized clinical trial of vocational rehabilitation for people with psychiatric disabilities. Rehabil Couns Bull. 2006;49:143.

38. Marini I, Lee GK, Chan F, Chapin MH, Romero MG. Vocational rehabilitation service patterns related to successful competitive employment outcomes of persons with spinal cord injury. J Vocat Rehabil. 2008;28:1-13.

39. Fraser RT, Johnson EK, Clemmons DC, Getter A, Johnson KL, Gibbons L. Vocational rehabilitation in multiple sclerosis (MS): a profile of clients seeking services. Work. 2003;21:69-76.

40. Khan F, Ng L, Turner-Stokes L. Effectiveness of vocational rehabilitation intervention on the return to work and employment of persons with multiple sclerosis. Cochrane Database Syst Rev. 2009;(1):CD007256.

41. Chan EY, Woo KW, Tang TM. Occupational rehabilitation services provided by a community workers health centre in Hong Kong: a case study. Work 2008;30:5-9.

42. Chan ML. Description of a return-to-work occupational therapy programme for stroke rehabilitation in Singapore. Occup Ther Int. 2008;15:87-99.

43. Lee R, Chan C. Factors affecting vocational outcomes of people with chronic illness participating in a supported competitive open employment program in Hong Kong. Work. 2005;25:359-68.

44. Gilworth G, Eyres S, Carey A, Bhakta BB, Tennant A. Working with a brain injury: personal experiences of returning to work following a mild or moderate brain injury. J Rehabil Med. 2008;40:334-9.
45. Burger H, Marincek C. Return to work after lower limb amputation. Disabil Rehabil. 2007;29:1323-9.

46. Li-Tsang CW, Li EJ, Lam CS, Hui KY, Chan CC. The effect of a job placement and support program for workers with musculoskeletal injuries: a randomized control trial (RCT) study. J Occup Rehabil. 2008;18:299-306.

47. Rothstein JM, Echternach JL. Primer on measurement: an introductory guide to measurement issues. Alexandria: American Physical Therapy Association; 1993.

48. World Health Organization. International Classification of Functioning, Disability and Health (ICF). Geneva, World Health Organization [webpage on the internet]. Available from: http://www.who.int/classifications/icf/en/.

49. Brage S, Donceel P, Falez F. Development of ICF core set for disability evaluation in social security. Disabil Rehabil. 2008;30: 1392-6.

50. Cieza A, Ewert T, Üstün B, Chatterji S, Kostanjsek N, Stucki G. Development of ICF core sets for patients with chronic conditions. J Rehabil Med. 2004;44(Suppl):9-11.

51. Young AE, Roessler RT, Wasiak R, McPherson KM, van Poppel $\mathrm{MN}$, Anema JR. A developmental conceptualization of return to work. J Occup Rehabil. 2005;15:557-68.

52. Sandqvist JL, Henriksson CM. Work functioning: a conceptual framework. Work. 2004;23:147-57.

53. Loisel P, Durand P, Abenhaim L, Gosselin L, Simard R, Turcotte $\mathrm{J}$, et al. Management of occupational back pain: the Sherbrooke model. Results of a pilot and feasibility study. Occup Environ Med. 1994;51:597-602.

54. Homa DB. Using the international classification of functioning, disability and health (ICF) in job placement. Work. 2007;29:277-86.

55. Ustun B, Chatterji S, Kostanjsek N. Comments from WHO for the Journal of Rehabilitation Medicine Special Supplement on ICF Core Sets. J Rehabil Med. 2004;44(Suppl):7-8.

56. Stucki G, Ewert T, Cieza A. Value and application of the ICF in rehabilitation medicine. Disabil Rehabil. 2002;24:932-8.

57. Schwarzkopf SR, Ewert T, Dreinhofer KE, Cieza A, Stucki G. Towards an ICF Core Set for chronic musculoskeletal conditions: commonalities across ICF Core Sets for osteoarthritis, rheumatoid arthritis, osteoporosis, low back pain and chronic widespread pain. Clin Rheumatol. 2008;27:1355-61.

58. Biering-Sorensen F, Scheuringer M, Baumberger M, Charlifue SW, Post MW, Montero F, et al. Developing core sets for persons with spinal cord injuries based on the international classification of functioning, disability and health as a way to specify functioning. Spinal Cord. 2006;44:541-6.

59. Grill E, Ewert T, Chatterji S, Kostanjsek N, Stucki G. ICF Core Sets development for the acute hospital and early post-acute rehabilitation facilities. Disabil Rehabil. 2005;27:361-6.

60. Scheuringer M, Stucki G, Huber EO, Brach M, Schwarzkopf SR, Kostanjsek N, et al. ICF Core Set for patients with musculoskeletal conditions in early post-acute rehabilitation facilities. Disabil Rehabil. 2005;27:405-10.

61. Stoll T, Brach M, Huber EO, Scheuringer M, Schwarzkopf SR, Konstanjsek N, et al. ICF Core Set for patients with musculoskeletal conditions in the acute hospital. Disabil Rehabil. 2005;27:381-7.

62. Pisoni C, Giardini A, Majani G, Maini M. International classification of functioning, disability and health (ICF) core sets for osteoarthritis. A useful tool in the follow-up of patients after joint arthroplasty. Eur J Phys Rehabil Med. 2008;44:377-85.

63. ICF Research Branch of the World Health Organization Collaborating Center of the Family of International Classifications. ICF Core Sets. Munich, Institute for Health and Rehabilitation Sciences, Ludwig-Maximillian University [webpage on the internet]. Available from: http://www.icf-research-branch.org/research/ reaserchprojects.htm. 
64. Marshall M, Bond GR, Huxley P. Vocational rehabilitation for people with severe mental illness. Cochrane Database of Systematic Reviews 2001; Art. No.: CD003080.

65. Gehanno JF, Rollin L, Le Jean T, Louvel A, Darmoni S, Shaw W. Precision and recall of search strategies for identifying studies on return-to-work in Medline. J Occup Rehabil. 2009;19:223-30.

66. World Health Organization. ICF Checklist. Geneva, World Health Organization [webpage on the internet]. Available from: http://www.who.int/classifications/icf/training/icfchecklist.pdf.

67. Sangha O, Stucki G, Liang MH, Fossel AH, Katz JN. The selfadministered comorbidity questionnaire: a new method to assess comorbidity for clinical and health services research. Arthritis Rheum. 2003;49:156-63.

68. Beck A, Steer R, Brown G. Manual for beck depression inventory-II. San Antonio: The Psychological Corporation; 1996.

69. Ware JE Jr, Sherbourne CD. The MOS 36-item short-form health survey (SF-36). I. Conceptual framework and item selection. Med Care. 1992;30:473-83.

70. The WHOQOL. Group. Development of the WHOQoL: rationale and current status. Int J Ment Health. 1994;23:24-56.

71. World Health Organization. ICD-10: International Statistical Classification of Diseases and Related Health Problems. 10th revision ed. Geneva: World Health Organization; 2007.

72. Cieza A, Geyh S, Chatterji S, Kostanjsek N, Ustun BT, Stucki G. Identification of candidate categories of the international classification of functioning disability and health (ICF) for a Generic
ICF Core Set based on regression modelling. BMC Med Res Methodol. 2006;6:36.

73. Blank L, Peters J, Pickvance S, Wilford J, Macdonald E. A systematic review of the factors which predict return to work for people suffering episodes of poor mental health. J Occup Rehabil. 2008;18:27-34.

74. Harding B, Torres-Harding S, Bond GR, Salyers MP, Rollins AL, Hardin T. Factors associated with early attrition from psychosocial rehabilitation programs. Community Ment Health J. 2008;44: 283-8.

75. Hagberg M, Tornqvist EW, Toomingas A. Self-reported reduced productivity due to musculoskeletal symptoms: associations with workplace and individual factors among white-collar computer users. J Occup Rehabil. 2002;12:151-62.

76. Krueger RA, Casey MA. Focus groups. A practical guide for applied research. 3rd ed. Thousand Oaks: Sage Publicastions, Inc.; 2000.

77. Sim J, Snell J. Focus groups in physiotherapy evaluation and research. Physiotherapy. 1996;82:189-98.

78. Boers M, Brooks P, Simon LS, Strand V, Tugwell P. OMERACT: an international initiative to improve outcome measurement in rheumatology. Clin Exp Rheumatol. 2005;23(5 Suppl 39):S10-3.

79. Bellamy N, Kirwan J, Boers M, Brooks P, Strand V, Tugwell P, et al. Recommendations for a core set of outcome measures for future phase III clinical trials in knee, hip, and hand osteoarthritis. Consensus development at OMERACT III. J Rheumatol. 1997; 24:799-802. 